\title{
Análise comparativa do desemprego por gênero no estado do Rio Grande do Sul dos anos de 2015 e 2018
}

\author{
Comparative analysis of unemployment by gender in the state of Rio \\ Grande do Sul in the years 2015 and 2018
}

\author{
Otávio Junio Faria Neves', Elinne Nastasha Carvalho Sousa Val", Italo do \\ Nascimento Mendonça'II
}

\begin{abstract}
RESUMO
Desde a gênese do mercado de trabalho no Rio Grande do Sul ocorreram diversas transformações e evoluções que foram importantes para a região. Em meio essas mudanças, destaca-se a inserção das mulheres no mercado de trabalho, processo que levou ao aumento de sua participação devido à busca por qualificação profissional. Todavia, as questões da desigualdade de gênero ainda perduram no mercado de trabalho regional e nacional. Há poucos estudos relacionados ao estado sulista sobre o assunto. Com isso, um dos objetivos dessa pesquisa é contribuir para a literatura regional. Para alcançar o objetivo desse estudo, verificaram-se as mudanças na composição do desemprego por gênero no estado do Rio Grande do Sul nos anos de 2015 e 2018, por meio da metodologia de Corseuil et al. (1997) e pelos dados da Pesquisa Nacional por Amostra de Domicílios (PNAD) contínua. Os resultados alcançados permitiram concluir que as mulheres têm reduzido a sua participação no desemprego e em contrapartida, os homens têm elevado a sua contribuição, sendo os fatores relacionados à demanda por trabalho fatores determinantes. Perante essas considerações, comprovou-se que as mulheres têm conquistado mais espaço no mercado de trabalho nos últimos anos, mas ainda assim, é preciso mais evolução para que a desigualdade se reduza cada vez mais.
\end{abstract}

Palavras-chaves: Gênero; Desemprego; Rio Grande do Sul.

\section{ABSTRACT}

Since the genesis of the labor market in Rio Grande do Sul, there have been several transformations and evolutions that were important for the region. Amid these changes, the insertion of women in the labor market stands out, a process that led to an increase in their participation due to the search for professional qualification. However, issues of gender inequality still persist in the regional and national labor market. There are few studies related to the southern state on the subject. Thus, one of the objectives of this research is to contribute to the regional literature. To achieve the objective of this study, changes in the composition of unemployment by gender were observed in the state of Rio Grande do Sul in the years 2015 and 2018, through the methodology of Corseuil et al. (1997) and data from the continuous National Household Sample Survey (PNAD). The results achieved allowed us to conclude that women have reduced their participation in unemployment and, on the other hand, men have increased their contribution, with factors related to the demand for work being determining

'Mestrando no Programa de Pós-Graduação em Economia pela Universidade Federal de Alfenas (UNIFAL-MG) otavionevescg@hotmail.com

" Mestranda no Programa de Pós-Graduação em Economia pela Universidade Federal de Alfenas (UNIFAL-MG) elinneval@gmail.com

III Mestrando no Programa de Pós-Graduação em Economia pela Universidade Federal de Alfenas (UNIFAL-MG) italovga@hotmail.com 
factors. In view of these considerations, it has been shown that women have gained more space in the labor market in recent years, but even so, more evolution is needed so that inequality is reduced more and more.

Keyword: Gender; Unemployment; Rio Grande do Sul.

\section{INTRODUÇÃO}

O mercado de trabalho tem atribuição fundamental na economia de um país, sendo importante para mensurar o nível de crescimento e desenvolvimento. Esse mercado se organiza na compra e venda de mão de obra, em que os trabalhadores e empregadores se defrontam, sendo um aspecto primordial para o funcionamento da economia.

A criação do mercado de trabalho no Rio Grande do Sul sucedeu-se no limiar do século XX e sua evolução ocorreu por meio do avanço industrial e das políticas públicas regionais e federais implementadas. Estudos recentes apontam que entre $o$ período de 1993 até 2002, houve uma grande evolução no mercado de trabalho sulista, questão importante para o crescimento da participação das mulheres no mercado de trabalho local.

Nas últimas décadas ocorreu uma importante transformação na inserção das mulheres no mercado de trabalho. Com a busca por qualificação profissional, as mesmas ganharam muito espaço. Porém, mesmo com todas as mudanças relativas à participação feminina no âmbito do trabalho, ainda persiste a questão da desigualdade de gênero.

Existem poucos trabalhos sobre o desemprego entre homens e mulheres no estado sulista, diante disso, a motivação desse estudo foi contribuir para a literatura econômica com os resultados e conclusões da pesquisa. Desse modo, o objetivo desse estudo é verificar as modificações na composição do desemprego por gênero no estado do Rio Grande do Sul nos anos de 2015 e 2018. Destarte, foi utilizado a metodologia de Corseuil et al. (1997) e os dados da Pesquisa Nacional por Amostra de Domicílios (PNAD) contínua para os respectivos anos.

A presente pesquisa parte da hipótese de que as mudanças na composição do desemprego por gênero no estado sulista são justificadas pelo lado da demanda do trabalho. Ou seja, a insuficiência de demanda no mercado de trabalho é determinante para o desemprego no estado e no país em geral. Assim sendo, o trabalho assumirá que o desemprego é involuntário, com base na fundamentação teórica keynesiana.

O estudo revela-se importante, pois trata de um dos problemas que mais afligem o bem-estar dos trabalhadores, das famílias e do próprio desenvolvimento da economia regional e nacional. Logo, entender os determinantes do desemprego é importante para que o governo tenha elementos para a tomada de decisão na aplicação de políticas públicas, visando à redução do mesmo.

Além desta introdução, a presente pesquisa está estruturada em quatro seções. Na primeira seção serão evidenciados os principais aspectos teóricos do mercado de trabalho e do desemprego, expondo os pressupostos clássicos e 
keynesianos. Na sequência será apresentado um panorama recente do mercado de trabalho no Rio Grande do Sul. Em seguida, serão expostas as taxas de desocupação do estado e por meio da metodologia serão apresentados os principais resultados da composição do desemprego. Por fim, serão apontadas as conclusões do estudo.

\section{ABORDAGEM CONCEITUAL DO MERCADO DE TRABALHO E DESEMPREGO}

Após a Revolução Industrial, as relações de trabalho entre empregado e empregador ganharam bastante destaque. Para elucidar o motivo de tamanha relevância esta seção se dedicou a explanar a respeito dos conceitos de referência. É importante compreender que a noção de mercado de trabalho, apesar de presente cotidianamente nos jornais e rodas de conversas, possui uma interpretação ortodoxa que se refere ao equilíbrio entre oferta e demanda de um fator de produção por um preço determinado (remuneração) (VARELLA e PIERANTONI, 2008).

O mercado de trabalho também é percebido como um espaço onde empregadores e empregados concebem as relações entre capital e trabalho, sob a interferência governamental (CHAHAD, 2004) - esta concepção é entendida como o modelo formal desta associação. Porém, essas relações também podem ser promovidas sem a tutela do Estado ou com mínima mediação, caracterizando o modelo informal. O uso da expressão "trabalho informal" é procedente dos estudos realizados pela Organização Internacional do Trabalho (OIT) na década de 1970, quando se analisava um grande contingente de trabalhadores vivendo de atividades econômicas alheia a qualquer proteção ou regulação pública por via de leis (VARELLA e PIERANTONI, 2008).

Para o Instituto Brasileiro de Geografia e Estatística (IBGE), o conceito de trabalho informal utilizado pelas estatísticas oficiais depende do tipo de posição na ocupação, as quais podem ser ocupadas por trabalhadores por conta própria ou trabalhadores sem carteira assinada (VARELLA e PIERANTONI, 2008). No que diz respeito ao perfil, sabe-se que uma parcela considerável do setor informal é constituída por trabalhadores com grau de instrução educacional baixo. Diante disso, esses indivíduos têm dificuldade para acessar oportunidades profissionais formais, sobretudo em tempos de crise econômica e/ou quando são intensificadas as mudanças na organização do processo produtivo, que requer trabalhadores multifuncionais cada vez mais, expondo aqueles que não se enquadram a situações de trabalho precárias, com baixas remunerações, supressão de direitos trabalhistas, aumento da jornada de trabalho, entre outras. De outro modo, também no setor informal, há uma fração de trabalhadores instruídos que optaram por buscar remunerações melhores do que as impostas pelo mercado e preferiram trabalhar por conta própria (VARELLA e PIERANTONI, 2008).

Ademais, o mercado de trabalho é classificado em clássico e keynesiano. Os estudiosos adeptos da primeira corrente de pensamento entendiam o mercado de trabalho como homogêneo e exíguo, por meio da ideia de que as empresas requisitavam mão-de-obra e os trabalhadores a ofertavam, em concorrência perfeita, 
cuja demanda seguia a função de produção da companhia, a qual contratava mãode-obra até o produto marginal se igualar ao salário real, enquanto a oferta de trabalho obedecia a utilidade do indivíduo entre lazer e trabalho. Com isso, os clássicos acreditavam que, sendo os preços e salários voláteis, e se houver flexibilidade da mão-de-obra e disponibilidade de informações, o mercado de trabalho tenderia ao equilíbrio com pleno emprego (OCIO, 1995).

Já a linha de pensamento keynesiana compartilha uma visão diferente, que entende o nível de emprego e o trabalho vinculados à atividade econômica, partindo da noção de que quanto maior for o investimento (público ou privado) e quanto maior for o consumo, melhor será o funcionamento do mercado de trabalho. Neste sentido, a interpretação dada ao equilíbrio entre oferta e demanda por mão-de-obra, na verdade, determina os salários nominais (e não reais, como para os clássicos), dado que, segundo seus defensores, os trabalhadores são acometidos pela "ilusão monetária" e desconhecem o salário real vigente na economia (NERY, 2012).

No âmbito conceitual, é primordial definir o desemprego, compreendido pela falta de trabalho quando há disposição para trabalhar, sem sucesso em ser contratado (VARELLA e PIERANTONI, 2008). Também existem os desalentados, que são um grupo de pessoas disponíveis para trabalhar, mas que não estão buscando emprego, cujo número tem crescido no período recente, motivado pela falta de trabalho na localidade e por não conseguir trabalho adequado, em virtude da idade e/ou da falta de experiência profissional ou qualificação (SABOIA, BAETA e GOMES, 2020).

Cabe ressaltar que há o desemprego natural, resultante dos impactos das transformações das técnicas de produção, do fluxo da força de trabalho ou alterações nos hábitos sociais, sendo entendido como desemprego voluntário pelos economistas clássicos e como um sinal de crise para os keynesianos (VARELLA e PIERANTONI, 2008). Outro tipo é o desemprego sazonal, decorrente das variações na demanda por mão-de-obra em períodos alternados no ano, como feriados e comemorações especiais (SOBRINHO e MONOLESCU, 2005). Também é válido mencionar o desemprego cíclico, causado pelas flutuações na atividade econômica e o friccional que corresponde ao intervalo ocasionado quando os trabalhadores deixam seus empregos por melhores posições de trabalho (SOBRINHO e MONOLESCU, 2005). Já o desemprego estrutural ocorre quando os trabalhadores não atendem às necessidades reveladas pela demanda por motivos de qualificação (SOBRINHO e MONOLESCU, 2005).

Da mesma forma que há diferenças quanto à interpretação sobre o mercado de trabalho, entre os clássicos e keynesianos, existem distinções na conceituação do desemprego. Os clássicos, partindo da lei de Say, consideram que o desemprego advém de uma opção por não trabalhar, motivado pelo salário ou por escolha individual, ou seja, acreditam que somente há desemprego voluntário, pois se considera que a oferta de trabalho se iguala à demanda por trabalho, cujas forças de mercado induzem ao pleno emprego (NERY, 2012). Por outro lado, a corrente keynesiana entende a existência exclusiva do desemprego involuntário, oriundo das 
ineficiências da demanda, a partir do desajuste macroeconômico entre a demanda efetiva e o produto potencial. Isto significaria, portanto, que havia por parte do indivíduo a disposição para trabalhar, mas ele não encontrava oportunidades para acessar.

Assim, diante da diferenciação conceitual, frisa-se que este trabalho tratará do desemprego fundamentado na interpretação keynesiana. Na seção abaixo, será feito uma análise do mercado de trabalho no Rio Grande do Sul, expondo as principais características e os aspectos recentes envolvendo os homens e as mulheres no mercado de trabalho local.

\section{PANORAMA RECENTE DO MERCADO DE TRABALHO NO RIO GRANDE DO SUL}

A formação do mercado de trabalho no Rio Grande do Sul (RS) ocorre no início do século $\mathrm{XX}$, com absorção do trabalho imigrante, principalmente em pequenas manufaturas do setor de bens de consumo não duráveis (HERRLEIN JÚNIOR, 2000). Sua consolidação apenas se difere no tamanho do mercado interno e no porte industrial, se comparado ao mercado de trabalho de São Paulo, principal centro urbano e industrial do Brasil na primeira metade do século.

Sua evolução ocorre em consoante ao avanço industrial e moldado pelas políticas públicas locais e federais, destacando-se a importância das garantias trabalhistas conquistadas e das lutas sindicais realizadas principalmente após o período ditatorial, na década de 1980 (POCHMANN, 2010).

Brumer (2004) aponta como a população do Estado do Rio Grande do Sul foi migrando para as cidades na segunda metade do século XX. Em 1950, 65,9\% do total morava no campo. Esse número diminui para 21,3\% em 1996. O êxodo rural é acompanhado pela inserção dos trabalhadores em diversos setores do mercado de trabalho: indústrias, serviços, comércio, administração pública, dentre outros.

A autora demonstra, em seu estudo, que o número de mulheres migrantes do campo para a cidade foi maior do que o número de homens. Esse processo se deu devido aos desincentivos para se manter no trabalho agrário, dada as desigualdades inerentes ao gênero, que concedem menores perspectivas profissionais no âmbito rural para as mulheres em comparação aos homens. Além disso, a expansão urbana e proximidade geográfica de centros industriais também corrobora essa constatação.

Segundo Sternberg (2001), no período entre 1989 e 1998 - momento em que o mercado de trabalho nacional foi drasticamente afetado pela abertura comercial e pelo desinvestimento industrial, com aceleração de demissões no mercado formal e aumento do número de trabalhadores que ingressaram no mercado de trabalho informal - o Rio Grande do Sul apresentou uma diminuição de 5\% de trabalhadores em empregos com vínculo formal. Isso compreendeu aproximadamente 95 mil postos de trabalho desocupados, principalmente na indústria de transformação, ao longo dessa década.

Jornada (2004) em um estudo detalhado sobre a evolução do mercado de trabalho no Rio Grande do Sul após a criação do Plano Real, aponta que, entre 1993 
e 2002, o crescimento da ocupação no Estado sulista foi de $8,9 \%$, enquanto o país registrou um aumento de $17,4 \%$. A autora aponta que tanto a nível nacional como a nível estadual, há uma crescente inserção das mulheres no mercado de trabalho e também o aumento do nível de escolaridade da força de trabalho.

As taxas de desemprego do RS entre 1993 e 2002 sempre estiveram abaixo que a média nacional: enquanto o Rio Grande do Sul registrou uma elevação de $4 \%$, no início da série, para 6,7\% em 2002, o país registrou um aumento de 6,2\% para 9,2\% (JORNADA, 2004). Evidencia-se que o desemprego entre as mulheres $(11,6 \%)$ cresceu mais do que para os homens $(7,4 \%)$, no final da série.

Realizando um estudo sobre a severidade do desemprego no Rio Grande do Sul entre 2001 e 2013, Arruda (2016) apresenta que 11\% do total de desempregados do Estado estavam nessa condição há mais de um ano. Isso configura que há certa dificuldade de reinserção para uma parcela dos trabalhadores, fato pelo qual o autor busca encontrar explicações na análise do perfil dessas pessoas.

Constatou-se que a maioria das pessoas que estavam com alguma dificuldade de se recolocar no mercado de trabalho eram, em sua média, mulheres, que somam $71 \%$ do total. Além disso, destaca-se que "pessoas não-negras, os jovens entre 15 e 25 anos, os não chefes de família, os residentes em área urbana e pessoas com ensino fundamental incompleto ou completo" também compõe o grupo de pessoas que demoram mais do que 12 meses para reingressar no mercado de trabalho, no Estado do Rio Grande do Sul (Arruda, 2016, p.127).

O autor aponta ainda que indivíduos do sexo masculino possuem uma probabilidade, em média, $5 \%$ menor do que o sexo feminino em se manter sem emprego por um período maior do que um ano. Isso reflete uma desigualdade notável em possibilidades de recolocação profissional no Estado.

Ainda sobre a desigualdade de gênero no Estado do RS, Jornada (2001) exibe que entre 1993 e 2002 há uma diminuição da discrepância entre o rendimento dos homens e das mulheres. Enquanto o rendimento médio real do sexo feminino no Estado foi de $68 \%$ em 1993, para 74\% em 2002, no Brasil, essa relação passou de $64 \%$ para $84 \%$. Ou seja, no RS, as remunerações das mulheres mostravam-se relativamente mais desvantajosas que a nível nacional. Porém, ainda se mostra evidente a desigualdade de gênero, seja a nível estadual como a nível nacional.

Comparando o mercado de trabalho do Rio Grande do Sul com o do Estado do Ceará na virada do século XXI, Carleial e Araújo (2011) exprimem que o emprego feminino representava uma força de trabalho com um nível educacional mais elevado e, portanto, mais qualificado do que o masculino, sendo esse fato resultado de fatores culturais, que delegam ao sexo feminino uma tradição de frequentar mais o ambiente escolar, enquanto os homens se retiram com antecedência da academia. Ou seja, há reflexos de uma mentalidade cultural evidentes no mercado de trabalho.

Porém, as autoras apontam que, mesmo com escolaridade maior - que deveria garantir, na teoria, salários em um patamar mais elevado - o sexo feminino na força de trabalho no Rio Grande do Sul ainda recebia menos do que os homens, 
reverberando a discriminação salarial eminente não só no RS mas no país como um todo.

Jornada e Sternberg (2001, p.71) exprimem que "apesar de terem diminuído as distâncias entre os rendimentos médios reais dos trabalhadores homens e mulheres, os diferenciais, no final do período observado, ainda eram acentuados". O período ao qual as autoras se referem é a década de 1990. Essa diferença salarial foi encontrada em todos os nove setores do mercado de trabalho expostos no estudo.

Pereira e Oliveira (2017), fazendo uma análise mais recente para os maiores municípios do Rio Grande do Sul, com base no Censo de 2010 realizado pelo Instituto Brasileiro de Geografia e Estatística (IBGE), apontam que o caráter de desigualdade salarial entre os gêneros ainda é notório no Estado, mesmo que as mulheres tenham quase $10 \%$ a mais de escolaridade do que entre os homens.

Não obstante uma melhora relativa na questão das desigualdades de gênero nos últimos anos na estrutura ocupacional brasileira até 2015 - as mulheres melhoraram sua posição no que tange às taxas de desemprego, renda média e aumento da formalidade - ressalta-se que a desigualdade ainda persiste e que fatores estruturais colaboram para isso, seja pela segmentação do mercado de trabalho (algumas profissões serem predominantes ocupadas por um gênero) ou pela segregação do sexo feminino em algumas funções (LEITE, 2017).

Comparando dados da PNAD entre as regiões do país, Sousa e Guedes (2016) demonstram que a região Sul é a que possui maior contingente de mulheres na População Economicamente Ativa (PEA) e também é o local em que homens contribuem mais com afazeres domésticos, se comparado às outras regiões. Porém, mesmo com a crescente participação da mulher no mercado de trabalho local e nacional, há muito que avançar para amenizar as desigualdades entre os gêneros.

Comparando o mercado de trabalho do Rio Grande do Sul com o do Brasil, Grzybovski et al (2001) afirma que as mulheres vêm cada vez mais ocupando cargos de trabalho que exigem algum grau de instrução mais elevado, porém, continuam sendo remuneradas de maneira inferior aos parceiros do sexo masculino. Visto isso, é necessário ampliar estudos de ambos os gêneros, de modo a tentar identificar outros fatores que contribuam para que a desigualdade ainda exista. Para isso, estudos econômicos sobre o mercado de trabalho dispõem de metodologias diversas: econometria, softwares de análise de dados, linguagens de programação e todo um ferramental para analisar dados a nível nacional ou local.

Em estudo recente sobre o mercado de trabalho no Brasil, Neto et al (2016, p.76) apontam que "mesmo com melhores taxas de ocupação, as mulheres estão mais propensas a se inserirem em ocupações precárias e instáveis, principalmente no mercado de trabalho informal". Outra constatação que os autores encontram é que a desigualdade de gênero não se dá de maneira homogênea entre as regiões do país, sendo a região Nordeste a que apresenta isso de maneira mais explícita.

Montali (2016) afirma que pelo panorama geral do mercado de trabalho no Brasil e tendo em vista a desigualdade de gênero latente em nosso país, é necessário implementar políticas públicas que busquem promover equidade entre os gêneros. 
Essas ações devem ser no sentido de aumentar a escolaridade dos adultos e de promover ações que garantam que mães tenham mais condições de trabalho, como, por exemplo, a criação de vagas em creches e melhorias no ensino fundamental e médio.

Na próxima seção, serão elucidados os resultados da taxa de desocupação do Rio Grande do Sul nos anos de 2015 e 2018, destacando-se a análise dos gêneros.

\section{TAXA DE DESOCUPAÇÃO DO RIO GRANDE DO SUL}

A taxa de desocupação é entendida como a relação entre a quantidade de indivíduos desocupados (buscando emprego) e a quantidade de indivíduos economicamente ativos em um determinado tempo (IBGE, 2020). O desempenho da taxa de desocupação deve-se a um conjunto de fatores econômicos, sendo a taxa de crescimento um aspecto importante no comportamento desta. Destarte, segundo os dados da Fundação de Economia e Estatística Siegfried Emanuel Heuser (FEE), o Produto Interno Bruto (PIB) do Rio Grande do Sul apontou uma variação negativa ($4,6 \%$ no ano de 2015, após uma redução de 0,3\% em 2014. Se comparar com o país, em 2015, o decrescimento foi maior que a do Brasil (- 3,5\%). Conforme os dados do Instituto de Pesquisa Econômica Aplicada (IPEA), no ano de 2018 o estado sulista obteve um desempenho de 1,22\% em sua atividade econômica, apresentando uma variação positiva. Tal desempenho foi semelhante ao do território brasileiro, em que a taxa de crescimento correspondeu a $1,1 \%$.

O desemprego é um dos problemas que mais consternam o bem-estar dos trabalhadores, sendo produto de vários aspectos, com ênfase para o ritmo de ampliação ou redução da economia. Os resultados desses fatores induzem a maior ou menor criação de postos de trabalhos. Assim sendo, verificou-se que no ano de 2015 o estado sulista passou por uma recessão no que tange a sua taxa de crescimento, e já em 2018 houve uma pequena melhora. Pelo fato do crescimento da economia ser fundamental para a geração de empregos, e pela ocorrência de um cenário de recessão em 2015 e em 2018 um leve crescimento, justifica-se a escolha dos anos nessa pesquisa.

No presente estudo foram utilizados os dados da PNAD com o objetivo de analisar os determinantes do desemprego por gênero no estado do Rio Grande do Sul. Nesta seção serão analisadas as taxas de desocupação total do estado e as taxas de desocupação das mulheres e homens nos anos de 2015 e 2018.

Na tabela 1 será apresentada a taxa de desocupação total do Rio Grande do Sul para os anos da pesquisa. Observa-se que houve um crescimento da taxa de desocupação total do estado, sendo que esta elevação foi de 5,33\% para 8,24\%. 
Tabela 1 - Taxa de desocupação total no Rio Grande do Sul para os anos de 2015 e 2018

\begin{tabular}{cc}
\hline Taxa de desocupação (U/N) em \% (da população total) \\
\hline 2015 & 5,33 \\
2018 & 8,24 \\
\hline
\end{tabular}

Fonte: Elaboração dos autores com base nos dados das PNADs contínuas.

Evidenciou-se um aumento de 54,59\% na taxa de desocupação do estado de 2015 para 2018. Os resultados permitiram concluir que ocorreu uma evolução do desemprego no Rio Grande do Sul, sendo o crescimento preocupante para a economia do estado, visto que a taxa de desocupação é um dos problemas que mais abalam o bem-estar das pessoas e este fator é um importante produto para atividade econômica da região.

Se compararmos as mesmas taxas com a do país, verifica-se que a média nacional aumentou em uma proporção maior do que a do estado, sendo equivalente a um aumento de $64,29 \%$ da taxa de desocupação do Brasil. O baixo dinamismo da economia tanto no país como no estado sulista pode ter influenciado o crescimento do desemprego, pois a expansão da taxa de crescimento de uma localidade é importante para a geração de empregos na sociedade.

Tabela 2 - Taxa de desocupação por sexo no estado do Rio Grande do Sul nos anos de 2015 e 2018

\begin{tabular}{lll}
\hline & \multicolumn{2}{c}{ Taxa de desocupação (Ui/Ni) em \% } \\
\hline & 2015 & 2018 \\
\hline Feminino & 7,03 & 9,60 \\
Masculino & 3,95 & 7,13 \\
\hline
\end{tabular}

Fonte: Elaboração dos autores com base nos dados das PNADs contínuas.

A tabela 2 demonstra que a taxa de desocupação das mulheres no estado sulista elevou-se em 36,55\% (7,03\% para 9,60\%). O aumento da participação feminina no desemprego pode ser justificado pela elevação das mulheres desocupadas em uma maior amplitude em relação à proporção das mulheres incorporadas na População Economicamente Ativa, o que colabora para elucidar o crescimento da taxa de desocupação feminina.

A taxa de desocupação dos homens também aumentou de 2015 para 2018, sendo esse aumento equivalente a $80,51 \%$ (3,95\% para 7,13\%). A justificativa desse aumento é idêntica ao das mulheres. Percebe-se que a elevação da taxa de desocupação dos homens foi bem maior do que as mulheres, mas ainda assim, elas detêm uma taxa de desemprego maior que a dos homens nos respectivos anos.

As conclusões desses dados concordam com o breve panorama do mercado de trabalho no estado sulista, pois as mulheres melhoraram sua posição no mercado de trabalho e suas taxas de desemprego reduziram. Porém, os dados também evidenciam que as desigualdades de gênero ainda perduram, sendo que as mulheres 
ainda têm uma taxa de desocupação maior que a dos homens, mesmo com a grande inserção delas no mercado de trabalho. Mesmo com o crescimento da participação das mulheres no âmbito do trabalho local e nacional, são necessários ainda muitos avanços para reduzir as desigualdades entre os gêneros no mercado de trabalho regional.

\section{MUDANÇAS NA COMPOSIÇÃO DO DESEMPREGO NO ESTADO DO RIO GRANDE DO SUL}

Para o presente trabalho, utilizou a metodologia proposta por Corseuil et. al (1997), no qual tem a finalidade de decompor o desemprego e verificar qual componente mais contribuiu para o mesmo. Seguindo o processo metodológico elaborado por Corseuil et. al (1997), a participação do grupo populacional i no desemprego do Rio Grande do Sul pode ser decomposta pelo seguinte termo:

Em que:

$$
\frac{\mathrm{Ui}}{\mathrm{U}}=\frac{\mathrm{Ui}}{\mathrm{Ni}} \times \frac{\mathrm{Ni}}{\mathrm{Pi}} \times \frac{\mathrm{Pi}}{\mathrm{P}} \times \frac{\mathrm{P}}{\mathrm{N}} \times \frac{\mathrm{N}}{\mathrm{U}}
$$

Ui: número de desempregados do grupo $i$;

$U:$ número total de desempregados;

Ni: número de indivíduos do grupo $i$ membros da PEA $^{1}$;

$N$ : número de indivíduos da PEA da localidade pesquisada;

$P i$ : número de indivíduos do grupo $i$ membros da PIA;

$P$ : número de indivíduos da PIA da localidade pesquisada;

A primeira equação pode ser reescrita pela seguinte maneira:

$$
\frac{\mathrm{Ui}}{\mathrm{U}}=\frac{\mathrm{Ui} / \mathrm{Ni}}{\mathrm{U} / \mathrm{N}} \times \frac{\mathrm{Ni} / \mathrm{Pi}}{\mathrm{N} / \mathrm{P}} \times \frac{\mathrm{Pi}}{\mathrm{P}}
$$

Ao converter a segunda equação em forma logarítmica, tem-se:

$$
\ln \left(\frac{U i}{U}\right)=\left[\ln \left(\frac{U i}{N i}\right)-\ln \left(\frac{U}{N}\right)\right]+\left[\ln \left(\frac{N i}{P i}\right)-\ln \left(\frac{N}{P}\right)\right]+\ln \left(\frac{P i}{P}\right)
$$

Por meio da terceira equação, pode-se obter:

$$
\Delta \ln \left(\frac{U i}{U}\right)=\left[\Delta \ln \left(\frac{U i}{N i}\right)-\Delta \ln \left(\frac{U}{N}\right)\right]+\left[\Delta \ln \left(\frac{N i}{P i}\right)-\Delta \ln \left(\frac{N}{P}\right)\right]+\Delta \ln \left(\frac{P i}{P}\right)
$$

Diante da última equação, elucida-se que a variação da participação dos indivíduos do grupo $i$ no estoque de desempregados da localidade pesquisada dependerá de três termos:

\footnotetext{
1 População Economicamente Ativa.

2 População em Idade Ativa.

A computação da PEA e PIA nesse presente trabalho foram elaboradas por meio da extração de dados da PNAD Contínua dos anos de 2015 e 2018.
} 
i) variação do desemprego do grupo em relação à variação do desemprego total da localidade pesquisada;

ii) variação da participação na PEA do grupo em relação à variação da participação na PEA da localidade;

iii) variação do peso do grupo na PIA da localidade pesquisada;

No primeiro termo admite-se que o desemprego foi motivado pelo lado da demanda por trabalho. O segundo e terceiro termo mostram as mudanças pelo lado da oferta por trabalho, que possuem características demográficas. Exposta essa metodologia, fundamenta-se indicar como os três componentes impactam as mudanças na composição do desemprego por gênero no Rio Grande do Sul, verificando a sua intensidade e o seu sentido.

Ademais, os valores negativos apresentados nos resultados apontam que o termo colaborou para a redução do desemprego. Em contrapartida, os valores positivos assinalam a contribuição para a elevação do desemprego. Na tabela 3 demonstra-se o comportamento da participação dos homens e das mulheres no desemprego total.

Tabela 3 - Decomposição do Desemprego de mulheres e homens nos anos de 2015 e 2018

\begin{tabular}{ccccc}
\hline Sexo & $\boldsymbol{\Delta} \ln (\mathrm{Ui} / \mathrm{U})$ & $\boldsymbol{\Delta} \boldsymbol{l n}(\mathrm{Ui} / \mathbf{N i})-\boldsymbol{\Delta} \ln (\mathbf{U} / \mathbf{N})$ & $\boldsymbol{\Delta} \ln (\mathbf{N i} / \mathbf{P i})-\boldsymbol{\Delta} \ln (\mathbf{N} / \mathbf{P})$ & $\boldsymbol{\Delta} \ln (\mathrm{Pi} / \mathbf{P})$ \\
\hline Masculino & 0,147 & 0,154 & $-0,016$ & 0,009 \\
Feminino & $-0,115$ & $-0,124$ & 2,320 & $-2,311$ \\
\hline
\end{tabular}

Fonte: Elaboração dos autores com base nos dados das PNADs contínuas.

Com base na tabela 3 verifica-se que os homens aumentaram a sua participação no desemprego total no estado do Rio Grande do Sul. O determinante para esse resultado foi o aumento da demanda por trabalho no grupo analisado. Por outro lado, houve uma redução da participação das mulheres no desemprego, sendo a diminuição dos fatores relacionados a PIA e os aspectos associados à demanda por trabalho preponderante nessa conclusão.

Destaca-se que mesmo com o aumento da População Economicamente Ativa no que se refere às mulheres, não foi suficiente para elevar a participação do grupo no desemprego. Essa redução das mulheres no estado do Rio Grande do Sul indica que a participação feminina no mercado de trabalho tem conquistado espaço na região.

Os resultados da decomposição entre os gêneros mostram que as mulheres estão reduzindo a sua participação no desemprego local, e os homens têm elevado a sua contribuição. Esses dados vão ao encontro no que foi dito na seção anterior, sendo que a taxa de desocupação das mulheres atenuou e o dos homens aumentou. Há muito por se fazer no âmbito da desigualdade de gênero, apesar dos dados já apontarem na melhora gradual e relativa deste aspecto, sendo necessária a continuidade dos esforços no sentido do equilíbrio do acesso ao mercado de trabalho, tanto local como regional e nacional. 


\section{CONCLUSÕES}

O presente estudo procurou contribuir para a literatura econômica no que se refere às pesquisas de desemprego sobre gênero no estado do Rio Grande do Sul. Desta forma, para alcançar esse objetivo foram examinadas as mudanças na composição do desemprego entre as mulheres e os homens no estado sulista nos anos de 2015 e 2018.

Os estudos recentes sobre a desigualdade de gênero no estado sulista e no Brasil mostraram que as mulheres cada vez mais têm ganhado espaço no mercado de trabalho, porém, ainda assim, a desigualdade persiste. Nesta pesquisa evidenciou que a taxa de desocupação das mulheres reduziu em uma maior magnitude em comparação aos homens nos anos de 2015 e 2018, mas mesmo com essa evolução, as mulheres detêm uma taxa de desemprego maior que a dos homens.

No que se refere às composições do desemprego entre os sexos, conclui-se que a participação feminina no desemprego se atenuou e os homens aumentaram a sua participação. E as justificativas para esses resultados foram a intensidade dos valores pelo lado da demanda do trabalho, concluindo que a insuficiência da demanda no mercado de trabalho impacta nos resultados do desemprego.

Conclui-se que está ocorrendo uma transformação positiva no âmbito do gênero no mercado de trabalho regional e local, no entanto, ainda assim a desigualdade de sexo tem sido um aspecto observado no âmbito do trabalho. Todavia, é fundamental que essa evolução continue, para que assim possamos amenizar cada vez mais a desigualdade entre as mulheres e os homens. Perante esse cenário, salienta-se que a ação estatal pode ser importante para reduzir discrepâncias no mercado de trabalho, seja no Rio Grande do Sul ou no país como um todo.

\section{REFERÊNCIAS}

ARRUDA, Elano Ferreira. Uma análise da severidade do desemprego no Estado do Rio Grande do Sul. Indicadores Econômicos FEE, v. 43, n. 4, p. 119-134, 2016.

BRUMER, Anita. Gênero e agricultura: a situação da mulher na agricultura do Rio Grande do Sul. Revista Estudos Feministas, v. 12, n. 1, p. 205-227, 2004.

CARLEIAL, Adelita Neto; ARAÚJO, Ana Maria Matos. Gênero e trabalho: comparando o Ceará com o Rio Grande do Sul. Mulher e Trabalho, v. 2, 2011.

CHAHAD, José Paulo Zeetano. Manual de Economia In: Pinho, Diva Benevides; Vasconcellos, Marco Antônio S. (Orgs.). Manual de Economia. São Paulo: Editora Saraiva, 2004, p. 381-405.

CORSEUIL, C. H. et al. A Rotatividade dos Jovens no Mercado de Trabalho Formal Brasileiro. Desafios à trajetória profissional dos jovens brasileiros. Brasília: IPEA, 2014, c. 5. Disponível em http://repositorio.ipea.gov.br/handle/11058/8445 Acessado em 14 de maio de 2020. 
CORSEUIL, C. et al. Determinantes da evolução da estrutura do desemprego no Brasil: 1986-1995. Economia Aplicada. São Paulo: USP, v. 1, n. 3, p. 443-467, 1997.

Fundação de Economia e Estatística Siegfried Emanuel Heuser (FEE). Indicadores. Disponível em : https://www.fee.rs.gov.br/indicadores/pib-rs/estadual/destaques/. Acessado em 10 de maio de 2020.

GRZYBOVSKI, Denize; BOSCARIN, Roberta; MIGOTT, Ana Maria Bellani. Mercado formal de trabalho e a mulher executiva. Teoria e Evidência Econômica, v. 9, n. 16, p. 79-100, 2001.

HERRLEIN JR, Ronaldo. Desenvolvimento industrial e mercado de trabalho no Rio Grande do Sul: 1920-1950. Revista de Sociologia e Política, n. 14, p. 103-118, 2000.

INSTITUTO BRASILEIRO DE GEOGRAFIA E ESTATÍSTICA. Pesquisa Nacional por Amostra de Domicílios. Disponível em:

https://www.ibge.gov.br/estatisticas/sociais/habitacao/17270-pnadcontinua.html?=\&t=microdados. Acessado em 10 de maio de 2020.

IPEADATA. Instituto de Pesquisa Econômica Aplicada. Macroeconômico. Disponível em: http://www.ipeadata.gov.br/Default.aspx. Acessado em 10 de maio de 2020.

JORNADA, Maria Isabel Herz. O mercado de trabalho no Rio Grande do Sul e o Plano Real: principais evidências. Indicadores Econômicos FEE, v. 32, n. 2, p. 223-246, 2004.

JORNADA, Maria Isabel Herz; STERNBERG, Sheila Sara Wagner. A mulher no mercado de trabalho formal do RS nos anos 90: notas sobre escolaridade e rendimento.

Mulher e Trabalho, v. 1, 2001.

LEITE, Marcia de Paula. Gênero e Trabalho no Brasil: Os desafios da desigualdade. Revista Ciências do Trabalho, n. 8, 2017.

MONTALI, Lilia. Desigualdades de gênero no mercado de trabalho e as políticas sociais. Anais do VIII Encontro Nacional de Estudos Populacionais, ABEP, Águas de Lindóia/SP, p. 1-15, 2016.

NERY, Pedro Fernando Ferreira de Almeida. Uma resenha teórica sobre o desemprego involuntário. Economia e Desenvolvimento, Recife (PE), v. 11, $n^{\circ} 2$, 2012.

NETO, Francisco Sergio De Almeida; COSTA, Marcia Da Silva; HELAL, Diogo Henrique. Relações de trabalho e gênero: aspectos da desigualdade no mercado de trabalho brasileiro. Cadernos de Estudos Sociais, v. 31, n. 1, p. 57-79, 2016.

OCIO, Domingo Zurrón. O EMPREGO NA TEORIA ECONÔMICA. Escola de Administração de Empresas de São Paulo Fundação Getúlio Vargas. NPP - Núcleo de 
Pesquisas e Publicações Série Relatórios de Pesquisa. Relatório de pesquisa nº 11/1995. Disponível em:

https://bibliotecadigital.fgv.br/dspace/bitstream/handle/10438/2951/Rel1195complet o.pdf?sequence=1\&isAllowed=y. Acessado em 14 de maio de 2020.

PEREIRA, Rafael Mesquita; DE OLIVEIRA, Cristiano Aguiar. Discriminação por gênero no mercado de trabalho local: um estudo para os municípios do Rio Grande do Sul. Análise Econômica, v. 35, n. 68, 2017.

POCHMANN, Marcio. Mercado geral de trabalho: o que há de novo no Brasil?. Parcerias estratégicas, v. 11, n. 22, p. 121-144, 2010.

SABOIA, João, BAETA, Fernanda e GOMES, Gustavo. Desalentados no Brasil Caracterização e evolução no período 2014/2019. UFRJ: Instituto de Economia. Rio de Janeiro, 2020. Disponível em https://www.ie.ufrj.br/images/IE/TDS/2020/TD_IE_003_2020_SABOIA_BAETA_GOMES.p df Acessado em 14 de maio de 2020.

SOBRINHO, Mauro Monteiro; MONOLESCU, Friedhilde Maria Kustner. O desemprego nas principais capitais do Brasil. IX Encontro Latino Americano de Iniciação Científica e V Encontro Latino Americano de Pós-Graduação - Universidade do Vale do Paraíba, 2005. Disponível em:

biblioteca.univap.br/dados/INIC/cd/inic/IC6\%20anais/IC6-10.DOC. Acesso em: 14 de maio de 2020.

SOUSA, Luana Passos de; GUEDES, Dyeggo Rocha. A desigual divisão sexual do trabalho: um olhar sobre a última década. Estudos avançados, v. 30, n. 87, p. 123139, 2016.

STERNBERG, Sheila Sara Wagner. A RAIS MIGRA como instrumento de análise do mercado de trabalho: um exercício a partir dos dados do Rio Grande do Sul.

Indicadores Econômicos FEE, v. 28, n. 4, p. 183-199, 2001.

VARELLA, T. C. e PIERANTONI, C. R. Mercado de trabalho: revendo conceitos e aproximando o campo da saúde. A década de 90 em destaque. Physis: Revista de Saúde Coletiva. Rio de Janeiro, 2008. Disponível em https://www.scielosp.org/article/physis/2008.v18n3/521-544/pt/. Acessado em 13 de maio de 2020. 